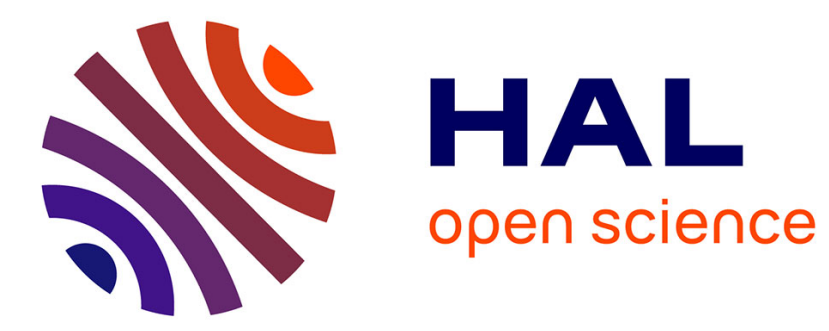

\title{
GRID INTEGRATION OF WAVE AND TIDAL ENERGY
}

\author{
Anne Blavette, Antony Lewis, Michael Egan, Dara O 'Sullivan
}

\section{To cite this version:}

Anne Blavette, Antony Lewis, Michael Egan, Dara O 'Sullivan. GRID INTEGRATION OF WAVE AND TIDAL ENERGY. OMAE2011, 2011, Rotterdam, Netherlands. hal-01265982

\section{HAL Id: hal-01265982 \\ https://hal.science/hal-01265982}

Submitted on 14 May 2018

HAL is a multi-disciplinary open access archive for the deposit and dissemination of scientific research documents, whether they are published or not. The documents may come from teaching and research institutions in France or abroad, or from public or private research centers.
L'archive ouverte pluridisciplinaire HAL, est destinée au dépôt et à la diffusion de documents scientifiques de niveau recherche, publiés ou non, émanant des établissements d'enseignement et de recherche français ou étrangers, des laboratoires publics ou privés. 


\title{
GRID INTEGRATION OF WAVE AND TIDAL ENERGY
}

\author{
Anne Blavette ${ }^{1}$ \\ Dara L. O’Sullivan ${ }^{1}$ \\ Antony W. Lewis ${ }^{1}$ \\ Michael G. Egan² \\ ${ }^{1}$ Hydraulics \& Maritime Research Centre \\ ${ }^{2}$ Department of Electrical Engineering \\ University College Cork, Ireland
}

\begin{abstract}
Wave and tidal energy provide a renewable source of electricity. However, their inherent fluctuations may have a negative impact on the power quality of a local electrical network. Grid operators assess this impact through the use of dynamic models of the generation units, which are inserted into the overall power system model. Providing these models is a compulsory step for any power generator to procure a grid connection above a specified power capacity. Significant issues were encountered in the wind energy industry regarding the dynamic modelling of devices, among which were model numerical instability, poor dynamic model quality and model incompatibility. Considering the large diversity of device types in the emerging ocean energy industry, these problems are considered as a major barrier to the larger scale grid-integration of marine energy converters. Dynamic models must clearly demonstrate the compliance of the actual power generation device and array of devices to the grid code requirements for grid-connection to be allowed. A further barrier to grid connection of ocean energy devices is that existing grid codes mainly written in the context of wind energy - may be irrelevant or inadequate for ocean energy devices. This paper presents an overview of these issues, and details a radically different approach to the dynamic modelling of ocean energy devices that will assist in overcoming the issues previously encountered in the development of wind turbine models. It also highlights the gaps and inadequacy regarding grid code requirements for ocean energy devices, and provides some recommendations for a new ocean energy grid code.
\end{abstract}

\section{INTRODUCTION}

Oceans and seas provide a renewable source of energy whose transformation into electricity is carbon-free. This is a significant advantage compared to common combustion-based conventional power plants. Marine energy is hence envisaged as a potential electricity source by many countries in order to reduce their carbon emissions and to diversify their sources of electricity. For instance, Ireland has set a target of $500 \mathrm{MW}$ of ocean energy in its energy portfolio by 2020 [1].

Besides, marine energy being a local resource, its integration into the energy mix would help to reduce the dependency on fossil-fuel of non-oil and gas-producing countries.

In the longer term, "Super Grids" projects [2] may include ocean energy and make it a significant source of electricity at the European level.

Although in its infancy, the ocean energy industry has the advantage of being in a position to benefit from the experience gained in the development of the wind energy industry. The variability and intermittency of wind resources, unknown to conventional power plants, has already set the foundations for new ways to operate the electrical network. These ways may need to be refined for operating the grid appropriately regarding the ocean power-specific characteristics in terms of variability and intermittency.

In order to preserve power system stability and power quality, grid codes have been revised to integrate requirements for wind turbines. Ocean energy having similar characteristics, these requirements are a relevant starting point for the development of specific requirements. Besides, numerical dynamic modelling of wind turbines has opened the way to dynamic modelling of variable power generation units in general, including ocean devices in particular.

\subsection{Dynamic modelling}

\subsubsection{Introduction}

For power plant above a minimum capacity (typically around 5MW) grid operators generally require the plant owners to provide dynamic models of their generation unit (e.g. conventional coal-fired unit, wind farm, etc.) before gridconnection can be allowed. These dynamic models reproduce the power plant's behaviour under both normal and fault conditions (e.g. short-circuits, sudden load increase, etc.). They are implemented in power system simulators, and the models must thus be compatible with such simulators.

\section{Objectives}

Power system simulators are the tool of choice for the assessment of impacts on the grid due to any system changes. They reduce the requirement of performing tests on the actual network, which may cause disturbances detrimental to customers as well as representing a potential threat to the grid stability. As well as being generally much easier to put in place 
than field tests, these numerical tests allow simulation of the power system behaviour for a full range of conditions, either external (e.g. outdoor temperature, wind speed) or internal (e.g. addition of electrical components such as generation units).

The decision to upgrade a part of the grid and/or install new generation units are usually taken on the basis of these simulations. Given the high economical, technical and human stakes, it is hence imperative that, the dynamic models implemented in power system simulators must be highly reliable and fully trusted.

\section{Impact on stakeholders}

Studies may be performed by grid operators to assess the compliance of a power plant with the grid code requirements. Providing a reliable dynamic model is hence crucial, as gridconnection is allowed only if simulations run with the numerical model demonstrate the compliance of the actual generation unit. Power system simulations also enable the grid operator to evaluate whether remedial work is required or not for facilitating the grid-connection of a power generation unit, for instance a wind farm.

\subsection{Experience acquired from wind energy development}

\subsubsection{Dynamic modelling of wind technology}

\section{Model issues}

Modelling of wind turbines or wind farms for power system studies has proven to be a major challenge. Since 2004, the transmission system operator of the Republic of Ireland (EirGrid) requires generation plant owners whose wind farm rating exceeds $5 \mathrm{MW}$ to provide dynamic models of their wind turbines for use in power system simulator PSS®E [3-4]. In a study published in 2007, it was demonstrated that of the 20 wind turbine models received by EirGrid from wind farm owners, none performed appropriately [5].

Tests showed that numerical instabilities occurred during simulations. Instabilities can also be observed at the simulation beginning due to a poor model initialisation. Wind turbines do not function at a fixed operating point: their power output varies with respect to the wind speed. Besides, the power output has several possible values for a single wind speed, because of the different blade angles.

Poor model quality was also a common issue. Only 8 of the 20 models received by EirGrid were actually designed for full power system stability studies. However, some of these 8 models requiring a simulation time step higher than the limit set by EirGrid (5 ms) did not pass the tests.

Some of these issues may stem from a certain lack of dialogue between wind farm developers and grid operators. On one hand, some developers did not fully understand what was expected from them. On the other hand, because of commercial confidentiality issues, the source code of models was not accessible to grid operators making the diagnosing of errors consequently much more difficult.

\section{Lack of confidence in model quality}

As mentioned before, the models must be reliable and trusted by all stakeholders. However, no standard test exists yet for the validation of these models against field measurements. Validation tests are often performed by manufacturers themselves or by independent entities on the grid operator demand, but in an uncoordinated, and hence potentially different way [6].

\section{Use of wind turbine dynamic models}

Another benefit from the wind energy industry is the existence of models for some wind turbine components similar to those used in ocean energy converters, such as drive-trains, gearboxes, generators and power electronics control blocks. Already existent numerical models of these components can be potentially used in ocean converter models, and hence no further modelling work is required for these particular model elements. Care must be taken though to verify that the dynamics of these models are compatible with the simulation of ocean energy devices.

\section{Conclusion}

Although a significant number of skilled teams have been involved in the process of wind turbine dynamic modelling for several years, reliable dynamic models have been released only quite recently [7]. This long development period underlines how challenging dynamic modelling can be. However, the experience gained in the modeling of certain components of wind turbines will be very useful to the ocean energy industry.

\subsubsection{Wind grid codes}

Grid codes define the requirements of both power plant owners/operators and the grid operator. The requirements imposed on power plant owners are mainly in place in order to assist in maintaining network stability.

Wind turbines and wind farms, like any other power generation units, must comply with these requirements. However, before a significant level of wind penetration was reached, no grid code requirement existed for wind power plants. Once wind energy became a non-negligible source of electricity, specific grid requirements were developed and have evolved along with the penetration level of wind energy.

The EWEA (European Wind Energy Association) has claimed that these requirements, as evolving too fast and sometimes with a short-time notice, were confusing for the industry [8]. The grid code requirements have had (and still have) a strong influence on the device development. For example, the decreasing interest in the robust and simple direct grid-connected squirrel-cage induction generator is partially due to its poor compliance with the low voltage fault-ride through 
requirement (as well as its reduced energy efficiency compared to variable speed designs).

Every time a new requirement is released, design changes are imposed on turbine or turbine equipment manufacturers, who may then have to revise their device design in order to restore its grid compliance.

Moreover, according to the EWEA [8], a lack of collaboration with the manufacturers and developers has led grid operators to establish requirements that were unfair to the wind industry. For instance, the EWEA affirms that the low voltage fault ride-through is not applied in a relevant manner in some regions or countries, as the local level of wind penetration is estimated by them to be still too low to be a threat to the grid stability.

The multiplicity of grid codes among regions or countries may also be a problem. For instance, similar words may correspond to different definitions whereas the same definition may be shared by two different words or acronyms. For instance, the point of connection of a power plant is called PCC (Point of Common Coupling) in Ireland, GCP in Spain (Grid Connection Point) [9] and Connection Point in Switzerland [10].

The ENTSO-E (European Network of Transmission System Operators for Electricity) has proposed to harmonise European grid codes for wind turbines [11].

This initiative is supported actively by the EWEA, which is working on a generic grid code for wind turbines [12]. This new tool would be very helpful for manufacturers who would have to develop only common hardware and software. It would also be beneficial to other stakeholders, from the developers to the customers, in particular by reducing the costs.

The generic grid code, as proposed by the EWEA, includes requirements to be applied all over Europe whose numerical values (e.g. voltage limit, maximum power ramp, etc.) can be specified by each network operator.

Another issue stemming from the current large number of grid codes is that the power system simulators used by grid operators may differ from one country to another. This might put a big stress on power plant managers regarding their dynamic model, as they may have to develop it under several simulator platforms.

In this case, it is likely that one original model created under one simulator will be exported or re-created under another. However, although the original model would be fully tested, it is not as likely that the alternative model will be tested to the same extent. In other words, the quality of models may differ among power system simulators, even for a single manufacturer.

\section{OCEAN ENERGY CONVERTERS}

\subsection{Introduction}

Figure 1 shows that ocean energy converters are highly diverse in both type and development stage.

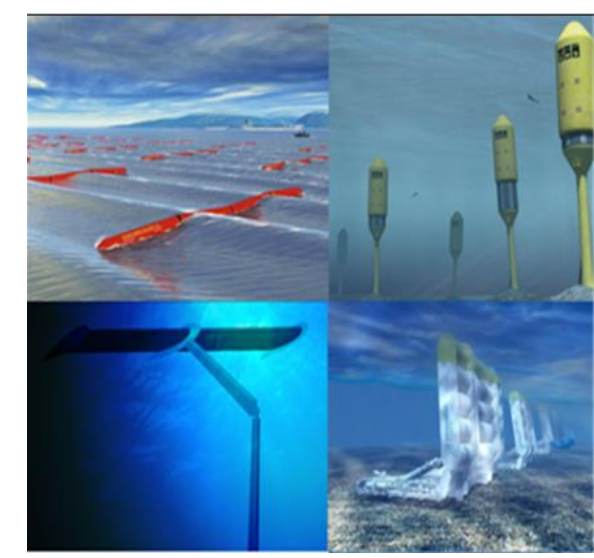

Figure 1 - Several types of ocean energy converters [13-16]

They are generally divided among wave and tidal energy converters, these categories containing other sub-categories. The EMEC website provides good descriptions of the main common types [17].

No concept among wave energy converters is currently emerging as the leading technology: almost all devices range from the detailed concept design stage to the test stage, few of them being at the pre-commercial stage.

In the case of tidal converters, the situation is similar apart from the notable exceptions of tidal onshore dams that are a tried and tested technology (e.g. la Rance barrage in France). However, the few sites suitable for such an application being already exploited (and their ecological impact ardently debated), the current challenge in the field of tidal energy is the realisation of reliable and efficient offshore tidal flow based non-barrage type devices.

\subsection{Inherent features of ocean electricity}

Apart from their different characteristics in terms of type and development stage, ocean energy converters are also very diverse regarding the quality of their output power, as well as regarding their behaviour during and after a grid fault. These features are of great interest to grid operators, but considering the relatively immature development stage of most devices, they have been investigated for relatively few devices. This absence of comprehensive studies on this topic results from the lack of data relevant to the electrical engineering field.

\section{Flicker}

Good power quality is necessary for the electrical network to work in a safe and reliable way but it is also an indicator that the network is operating as intended as well. A high flicker level is an indicator of a poor power quality. It designates power variations ranging from a few seconds to a few hours, perceivable by customers as bulb light flicker. It can be created by variations in the power generation or consumption on the grid, either by generators or loads, or by frequent switching on or off. Ocean energy converters, and especially wave converters, 
may be very likely to produce flicker considering the variability of their input power.

The flicker level potentially created by ocean energy converters depends as much on the local network as on the variability of their output power. For a given power variability, flicker level is likely to be greater on weak grids (i.e. usually low voltage, rural grids where the $\mathrm{X} / \mathrm{R}$ ratio is low), than on stronger (higher voltage, highly interconnected) grids. Inconveniently, the greatest European ocean energy resources are located off the western coasts of Ireland, as shown in Figure 2, and Scotland, which possess weak grids.

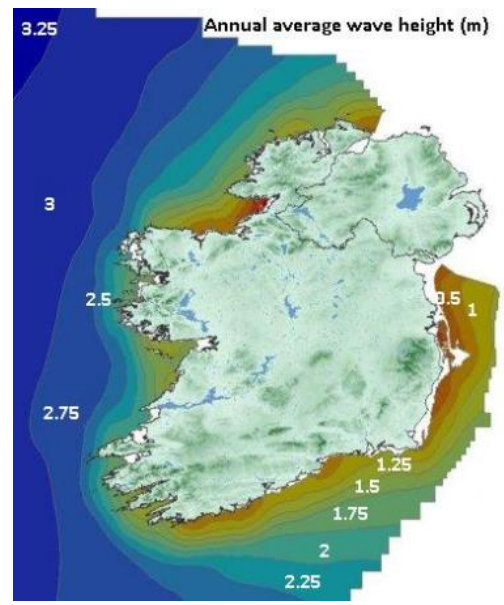

Figure 2 - Wave resources of Ireland [18]

Hence, the impact of a device cannot be determined according to its own characteristics only and specific studies have to be carried out for each potential connection site.

Keeping in mind that flicker is highly dependent on the local network, three categories should be distinguished regarding power output variability. The first category concerns devices having a relatively smooth input power leading to a smooth electrical power. This category includes tidal turbines that use tidal stream to produce electricity in a similar manner as wind turbines utilise wind velocity.

The second category is related to devices whose input power may be significantly variable but whose output power variability is mitigated by the inherent features of the device or device farm. This category includes devices having significant storage means (e.g. reservoir, fluid accumulator). It also includes device farms whose layout may smooth power variability significantly [18]. The last category includes the devices whose input power variability is not smoothed by any means and is thus transmitted to the electrical output power.

\section{Low voltage fault-ride through (LVFT)}

The occurrence of grid faults, such as short-circuits, deteriorate the quality of distributed power. Grid fault handling includes fault clearing as well as system recovery. Clearing the faults in a minimum amount of time is of the utmost importance as they may threaten the power system stability. However, too long a recovery can also lead to new faults or directly to system instability. Hence, strict requirements are applied to power generation units during the system recovery phase as well.

In the past, wind turbines were asked to disconnect at the occurrence of a fault. This stemmed from the wide use of direct grid-connected squirrel-cage induction generators whose reactive power absorption is not controllable. During a fault, the amount of reactive power absorbed by the wind turbines would have been significant and would have hence reduced the local voltage even more. This may have aggravated the initial fault and led to a spreading of the fault or to instability.

As long as wind turbines represented only a small share of the generation mix, forced disconnection was not an issue for power system stability. However, when the penetration level of wind energy becomes significant enough, as it is nowadays in some regions or countries (e.g. Denmark, Germany), this sudden shedding of wind power becomes also a potential threat to system stability.

Hence, wind turbines are now required by grid operators to remain connected during a fault. Moreover, they must support the network during and after the fault by supplying reactive power, in order to assist in system recovery. This behaviour is similar to the reaction of a synchronous generator in such a case.

This is called the low voltage fault-ride through requirement. The grey zone in Figure 3 shows the conditions with respect to which a wind turbine must stay connected [20].

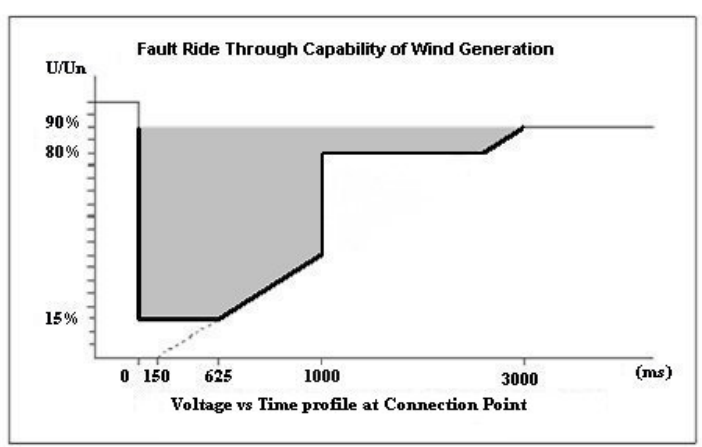

Figure 3 - Low voltage fault ride-through (Republic of Ireland)

Direct grid-connected squirrel-cage generators with their poor LVFT behaviour were progressively abandoned to the benefit of other generators types.

A large majority of ocean energy devices are planned to be connected to the grid via either fully or partially rated power electronics [21].

Power electronics enable ocean devices, to provide a controlled fault current and reactive power during a fault. Only a small minority of developers intend to connect their devices directly to the grid, similarly to the grid-connection pattern of wind turbines in the 1980's. The low voltage fault ride-through requirement, considering the wide use of power electronics for the grid-connection of marine energy converters, should not hence be such a major issue for the ocean energy industry as it was for the wind industry. 
Another option for improving the low voltage fault ridethrough behaviour of devices may be the integration of controlled storage means (either inherent or inertial).

A significant inertia, created for instance by the adding a flywheel to the rotor, may limit the acceleration rates during faults. In terms of inherent storage, reservoirs or fluid accumulators, if appropriately controlled, may also provide a sufficient energy buffer to absorb input power during a fault.

However, this option does not seem to be currently being investigated by ocean converter developers, hence reducing the advantage of having inherent or inertial storage means with respect to the fault behaviour. This may be due to lack of knowledge regarding these benefits more than any other reason.

\section{Impact on angular stability}

A large majority of conventional generators are synchronous machines. These machines are operating in synchronism with respect to the network frequency and at a phase angle to the connection point known as "load angle". This load angle must remain in a certain range for the machine to work in a stable manner. Variations in the load angle may be induced by local variations of power consumption or generation. The potentially fast and large power variations induced by nearby wave converters may make this load angle go beyond its stability limits. This would result in a loss of synchronism of the synchronous generator that would hence get shut-down. The loss of generation units is considered as a fault and may lead to consequent faults or instability.

\subsection{Conclusion}

As ocean energy converters are still mostly at the development stage, it is difficult to draw any definitive conclusions regarding their eventual impact on the electrical network. The analysis explained in this paper is based on the current features of such devices and on the still limited knowledge available on ocean converters' impact on power quality. However, it is already certain that some issues will arise, although their impact cannot be quantitatively characterised yet. These issues, detailed in the paper, need to be tackled early in order not to hinder the development of the ocean energy industry. Some existing solutions have been described and other remedial options proposed.

\section{GENERIC MODELLING OF OCEAN ENERGY CONVERTERS}

\subsection{Introduction}

Generic modelling has been highlighted as being a potential approach to solve the issues encountered by grid operators with the wind turbine-specific dynamic models [5].

The structure of a generic model must include all dynamic features of devices that are relevant to power system stability studies. It is hence common to a majority of devices and must be parameterised by device-specific data.

A generic model for wind turbines has appeared recently [22]. However, its wind speed is assumed constant and its dynamic features limited, so the model is consequently not suitable for the analysis of wind speed variations effect on the grid. This highlights one of the challenges of generic modelling: the very device-specific and highly complex dynamic response of any device must be reproduced using a minimum data that manufacturers can provide and using a simple and generalised pattern. Hence, there is as yet no fully dynamic generic model for wind turbines, despite the advanced stage of development of this industry.

It has been repeated in this paper that ocean energy devices are very diverse in type. This diversity, along with the experience acquired in wind turbine modelling, makes the generic modelling approach highly attractive instead of asking developers to supply a specific model for the many different device types.

However, this diversity is also what increases the difficulty of the generic modelling of ocean energy devices. It must be noticed that no generic model for wind turbines has been issued yet, although an overwhelming majority of wind turbines rely on the same 3-blade Danish concept. Hence, although the wind energy industry has opened the way to generic modelling, this topic is still at a very early stage of research and its complexity is dramatically increased in the field of ocean devices.

\subsection{Model validation}

Validation of dynamic models against field measurements was highlighted to be an issue in the wind energy industry, as no standard for tests currently exists.

The development of such standards should be addressed as early as possible. They would help to strengthen confidence in early stage models or to determine more precisely the refinements or adjustments required in them.

Common standards for the assessment of ocean energy device performance are still under development [23-25]. This work on the performance of actual devices may be a useful benchmark and signpost for the development of standards for the validation of numerical dynamic models.

\subsection{Additional advantages of generic modelling}

Generic modelling may offer added advantages related to the issue of portability between different power system simulators.

It has been mentioned that the use of various simulators by grid operators, such as PSS®E, DIgSILENT Power Factory, PSCAD®, DSATools ${ }^{\mathrm{TM}}$ [26-28], or of various versions of the same simulator, may lead to a variable quality in the models. This may stem from the modelling itself (for instance if one model is more tested than the other) or from errors in the transfer process between different simulators. 
The generic model structure would be publicly available. This would help grid operators to implement this structure into their own simulators and have it ready and checked before performing detailed modelling on ocean energy devices.

Moreover, since the generic model structure does not in itself contain commercially sensitive data, it can be widely published and discussed. Its quality can hence be greatly improved in a shorter period of time than in the case of confidential models.

The concept of a generic model is also considerably beneficial for ocean converter developers themselves. First, it reduces the large programming effort required by specific modelling of their device. Having a generic model structure available, along with a means to populate it with their own test or specification data may also mean that they may not need to purchase expensive power system simulator software. These considerations may be valid at an early stage of ocean converter grid-integration only.

\subsection{Conclusion}

Generic modelling is a useful approach to overcome issues similar to those encountered in the wind energy industry, as well as issues typical of the ocean energy industry. It is highly beneficial to ocean converter developers in reducing the programming effort and financial outlay, which may have been insurmountable for small teams. However, in order to sustain this initiative, it will be necessary to develop standards for the validation of data provided by the developers. The lack of strict specifications may lead developers to provide data for the model on the basis of different tests, with all the implications this may have in terms of model accuracy and stakeholders' confidence regarding this model.

In conclusion, the development of a generic model still represents a challenge. However, once achieved, it will greatly push the development of the ocean energy industry forward in tandem with standardisation of the model validation process. This will give more transparency to these processes and increase the confidence and mutual trust of all stakeholders.

\section{GRID CODES FOR OCEAN ENERGY CONVERTERS}

\subsection{Inadequacy of existing grid codes}

At the moment, no grid code requirement for ocean energy converters has been issued yet. Most research papers looking at the grid integration of ocean electricity refer to those already applied to wind turbines or wind farms. However, it is most likely that dedicated grid requirements will have to be issued for ocean energy converters considering their specific characteristics in terms of impact on power quality and system stability.

Some wind turbine requirements may not be fully suitable for ocean converters, especially those involving power quantities. As for wave energy converters, the maximum power peak can be equal to several times the average power. Figure 4 shows the electrical power output of a wave device without power mitigation means.

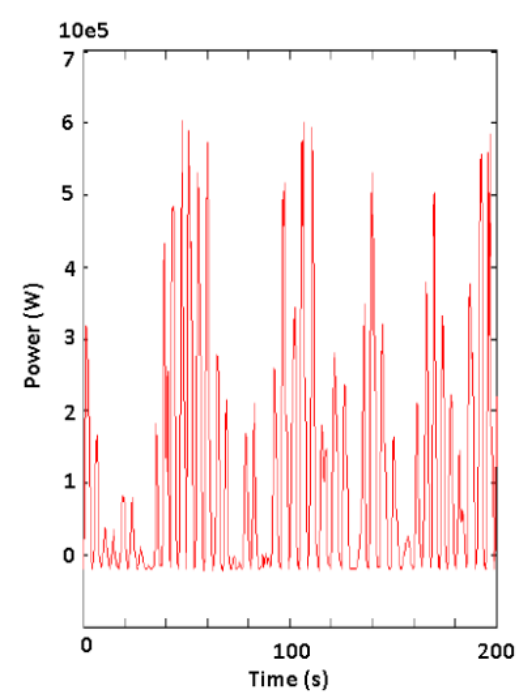

Figure 4-Example of electrical power output of a wave device without power mitigation means

Future grid code requirements must hence specify very clearly if the word "power" refers to peak or average power. Peak power may not be relevant as it is potentially reached for a very short duration during the wave cycle. On the other hand, average power is not a good indicator of the potential stress applied on the local electrical components.

Grid codes impose limits (either maximum or minimum) on power ramp rates [29]. These limits cannot be applied in practice to some wave energy converters whose power output is similar to the one shown in Figure 4.

Another issue concerns dynamic models. Some grid operators require developers to supply a dynamic model if the power plant capacity exceeds a specified limit (5 MW in the Republic of Ireland). This limit above which dynamic models must be provided is determined according to a certain level of risk regarding power system stability. However, output power variability may also play an important part in increasing this risk. Hence, a device rated at $1 \mathrm{MW}$ delivering highly variable power may impact grid voltage and stability to a greater degree than a wind turbine of $2 \mathrm{MW}$ supplying a relatively smooth short term power output. Hence, rated power of the generator is no longer a sufficient reference criterion for the development of grid code requirements.

Other grid codes [30] use a rule-of-a-thumb that may have to be re-examined. It is specified in these codes that voltage variations up to $3 \%$ at the point of common coupling may be allowed. However, this rule was established not taking into account the fast and frequent power variations potentially induced on the grid by ocean energy converters. These variations may be very different in terms of impact than the (not so regular) 
starting up or the shutting down of loads and generators for which this requirement was established.

\subsection{Impact of grid codes on the development of the energy industries}

As mentioned in the previous sections, grid code requirements greatly influence the development of energy devices. Above a specified power capacity, devices or device farms must pass grid-compliance tests to be allowed gridconnection. Making them technically grid-compliant is hence the only way for them to become marketable.

Developing grid codes, preserving power system stability as well as enabling a sustainable growth of the renewable energy industry is widely recognised as a significant challenge of the coming renewables era.

\section{RECOMMENDATIONS}

\section{1) Involvement of the ocean energy industry in the development of its specific grid code requirements}

The implementation of new grid code requirements for wind may have been perceived as unfair or unjustified by the wind energy industry [8].

In the case of ocean energy, a strong collaboration between grid operators and the developers regarding the grid code requirement development should be beneficial to both parties. Ocean converters, as mentioned before, are very diverse and it may be difficult for grid operators to get a complete insight into the potential impact on the grid of all the different brands of device. Having more dialogue with the ocean energy industry could lead to the development of more appropriate requirements, satisfying both parties. On the other hand, the involvement of the ocean energy industry in the development of these requirements would lead to a better acceptance from developers. Besides, it might improve the understanding of the industry regarding the full range of power system stability issues if needed.

Considering the currently large number of wave and tidal converter developers, it would be much more efficient, as well as more convenient, that organisations representing the industry discuss directly with grid operators. Many countries and regions in the world already use this system, for instance Europe with the European Ocean Energy Association (EU-OEA), New Zealand with the AWATEA, and North America with the Ocean Renewable Energy Group and the Ocean Energy Council. Although the development of ocean energy is still limited in some countries, the creation of such regional or national organisations should be strongly encouraged in order for grid operators to have relevant dialogue partners.

\section{2) Evolution of grid code requirements with respect to the penetration level of ocean energy}

Grid code requirements for wind turbines have evolved over the years due to the increasing penetration level of wind energy and to the improving understanding of wind turbines' behaviour under both normal and fault conditions. The first requirements demanded that wind turbines disconnect in the event of a grid fault, whereas current requirements impose them to stay connected. Requirements evolution is key in the integration of new sources of energy. In the case of ocean energy converters, it is proposed to divide this evolution among several steps to be determined in collaboration between the industry and grid operators. It is proposed that these future requirements evolve similarly to wind turbines' ones, hence according to the experience acquired at each stage of the grid integration process and according to the penetration level of the ocean energy in the energy mix. It would be unjustified, as well as irrelevant, to develop fixed requirements intended to be applied from low to high penetration levels.

\section{First phase}

This first phase of grid integration concerns the period in which the ocean energy share in the energy mix is negligible and hence does not threaten power system stability. During this period, soft grid requirements are recommended, so that developers can improve their technology by testing them entirely in real operating conditions, with grid connection. The relative lack of requirements or their softness during this first phase has been beneficial to the wind energy industry. During this period, wind turbine manufacturers have greatly improved the aerodynamic, mechanical and electrical performances of their devices, as well as their acoustic and aesthetic designs Figure 5 shows on the left some wind turbines located at the Tehachapi pass, California, whose development began in the early 1980s. The offshore wind farm on the right is located off Copenhagen, Denmark and was built in 2000 .
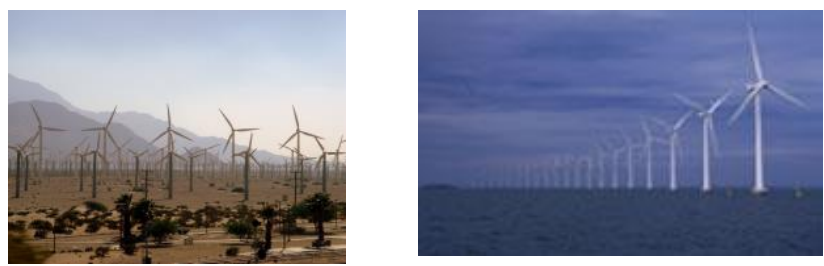

Figure 5 - Evolution of wind farm aesthetics [31-32]

This phase also enabled manufacturers to tackle more general issues, such as storm stand-by mode, lightning protection, aviation radar detection, etc.

\section{Later phase (s)}

Once the share of wind energy has become significant in some regions, stricter requirements have been applied, such as the low voltage fault ride-through or the frequency control requirements for instance. Similarly, stricter requirements must be implemented at a later stage, according to the penetration level of ocean energy. 


\section{Determination of key penetration levels}

Key penetration levels of ocean energy for each phase should be determined by grid operators with respect to the grid code requirements applied at the given phase. The potential occurrence of a fault on the grid or a significant decrease of power quality due to ocean energy converters would be unfavourable to both grid operators and the industry. In particular, it would decrease the confidence of all stakeholders in the technology (not only grid operators but also governing bodies) and also be very detrimental with respect to public acceptance. Such key levels must hence be determined very carefully and reasonable security margins should be applied in a conservative manner.

Grid operators should determine key steps in terms of penetration level with respect to the risk represented by the ocean power generation park. In other words, a key penetration level is determined once it is diagnosed (through simulation) that the requirements applied to ocean energy converters are not strict enough to preserve power system stability. At this stage, stricter requirements must come into effect for the power system to continue operating satisfactorily.

The analysis should be carried out at two levels: both local and national (or even international if the national network is part of a bigger network). In contrast to wind farms, typically geographically scattered relatively widely over the national network, ocean farms will logically be concentrated near or off the shore. Hence, national level studies must be carried out, but it is equally important to know how ocean converters may impact the local coastal network in terms of power quality and local power system stability.

Due to the concentration of ocean converters near or off the shore, the impact of a forced disconnection of these devices during a fault may have a greater impact on the network stability for a given number of ocean devices than for a similar power capacity of wind turbines. Hence, the low voltage fault-ride through requirement may have to come into effect earlier in the development process of the ocean energy industry than it did for wind turbines.

The still considerable knowledge gap with respect to the grid impact of ocean devices (due to their potentially high power variability) may require grid operators to require dynamic models from developers at a very early stage as well.

\section{3) Discussion of the evolution of grid codes early in the process of ocean energy grid integration}

It has been explained in previous sections how grid codes requirements have greatly influenced the development of wind turbines. It is certain that the grid code requirements for ocean converters will also have a very important impact on their development.

By using the EWEA as a mouthpiece, the wind energy industry has let it be known that grid codes for wind energy were changing too fast, and with too short notice. This lack of clarity regarding future requirements is also confusing for both the industry and the electricity producers. In order to provide the industry with some guidelines regarding the future and give it reasonable time to adapt to new requirements, it is proposed that the possible future evolutions of grid codes should be discussed very early in the process of ocean energy grid integration. However, developing requirements at such an early stage does not prevent their modification if needed according to the experience gained at each phase.

\section{4) Positive discrimination with respect to power quality of output electricity}

A majority of ocean converters being near-shore or offshore devices, the grid-connection of ocean farms will require a new and costly power system infrastructure to be built. In the first years, the process is likely to be restricted to few sites in the world that may also be used as test sites at first stage.

Each site will have a limited capacity for grid-connection depending on the strength of the electrical network it belongs to. Hence, the number of permits will be limited and competition may take place between developers to get their device gridconnected.

It is proposed that the selection among the devices to be connected to the grid is based on the optimum combination between efficiency, cost and power quality of the electricity produced (the latter often being omitted in techno-economic analysis). These suggestions imply that power quality of ocean energy converters is characterised in a clear and transparent way. Such standards are currently under development by the IEC technical committee TC 114. Besides, as it has been highlighted in the previous sections, utilising reliable numerical models of ocean energy converters is critical. Standards dedicated to model validation against field measurements must also be developed.

\section{5) Harmonisation of grid codes}

Harmonisation of grid codes is discussed among European transmission system operators. The EWEA supports this initiative and promotes the development of a generic grid code for wind turbines.

These two complementary initiatives, if adapted to ocean energy converters, would facilitate their grid integration on a large scale. Besides, the use of harmonised grid codes will become more and more necessary if initiatives such as the construction of an offshore "super grid" are realised.

\section{6) Additional power system study}

Grid operators typically perform network analyses for high and low load periods (usually winter and summer peaks and troughs respectively in the north of Europe). In regions with a high penetration level of wind energy, the wind seasonal variations are also taken into account.

Similar studies taking into account the seasonal variability of ocean energy must be performed. Concerning tidal energy, its 
variability at a weekly level may have to be taken into account as well.

However, it may be interesting to introduce a new study regarding power variability at shorter timescales. As ocean electricity, in particular wave electricity, may be highly variable and add significantly to the flicker level on the grid, periods of high and low flicker level must be studied as well. These periods may range over a day or a week. For instance, flicker level may be more important during the evening peak because of the large number of appliances switching on or off at this time.

This test regarding flicker may not be as relevant for countries such as Ireland or Scotland for instance, since their marine energy resources are located mainly off rural areas, with a very scattered population. However, the test may be relevant in countries or region with dense coastal population, for instance in Portugal. Figure 6 shows the population density of Portugal and Ireland.
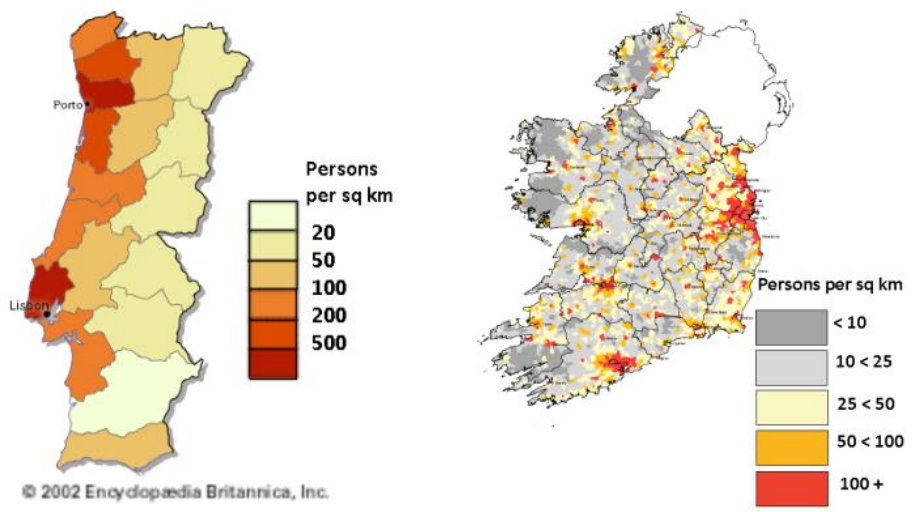

Figure 6 - Population density in Portugal and Ireland [33-34]

\section{7) Handling of power variations}

Grid operators may require devices to deliver power with a minimum level of power variation. As for wave energy converters, these variations may be significantly smoothed (relatively to the installed power capacity) due to the aggregation effect occurring in an array of devices [19]. This power smoothing effect is due to the arrival of waves at different times at the converters. Hence, it may be easier to mitigate the power variations of a wave farm rather than smoothing the individual power output of single devices. In the case of an ocean farm, the potential requirements regarding power variability must be applied to the farm rather than to the individual devices.

In order to determine the maximum power variations to be mitigated, devices should be tested over one year in order to undergo all the annual typical sea conditions. However, these annual sea conditions may not be absolutely similar over the years: one winter can be particularly stormy whereas the previous one was quieter. With this respect, the maximum power variation cannot be deterministically characterised and in the occurrence of large input power variation, power peaks may be transmitted to the rest of the grid. Because of these reasons, it may be important for the grid operator to install some additional mitigation means -through energy storage or energy removal for instance - in order to deal with such infrequent power peaks.

Grid operators may also choose to become more involved in the power smoothing process by supplying larger mitigations means, and thus removing some of the burden from the ocean energy industry. Besides, if a wave farm is composed of several device types belonging to several developers, it may be difficult to determine what the distribution of costs relative to these mitigation means would be.

This topic must be studied more in detail because of its multiple underlying implications. For instance, the implementation of fluid storage means on individual devices may decrease its overall efficiency and increase its costs. On the other hand, whereas mitigating the wave farm power output only may decrease the relative size of these means, it may also put a larger stress on the wave farm electrical components (cables, generators, etc.). An optimum solution with respect to power quality, cost and efficiency must be sought.

\section{CONCLUSION}

The paper has briefly presented the evolution of grid codes and dynamic modeling induced by the increasing gridintegration of wind turbines. A parallel has been established between wind and ocean energy characteristics so as to extract relevant feedback from the wind energy experience in those topics. A more detailed analysis has described the issues of dynamic modeling both common with wind turbines and typical to ocean energy converters only. Some inadequacies of the current grid codes with respect to the inherent characteristics of marine energy devices have been highlighted.

Grid codes requirements are intended to enable a safe, reliable operation of the electrical networks in order to preserve the overall stability of the power system. The current grid management emulates the operation of former networks whose generators were exclusively synchronous and fully-dispatchable. This type of networks has proven over the past century to perform extremely well, as well as being relatively easy to operate. Nowadays, wind generators are required to reproduce this typical behaviour (low voltage fault-ride through, participation in frequency control) and so it is likely to be similar for ocean generators in the future. The development of new requirements is hence not a simple adaptation work but a constant challenge: grid codes must be specific to new generation technologies, whose features may be radically different. This paper has proposed some recommendations regarding this development.

\section{ACKNOWLEDGMENTS}

The authors wish to thank Science Foundation Ireland, and more especially the Charles Parsons Initiative for funding their research. 


\section{REFERENCES}

[1] "Delivering a sustainable energy future for Ireland - The Energy Policy Framework 2007-2020”, Government White Paper

[2] "The North Seas' Countries Offshore Grid Initiative, Memorandum of Understanding", $3^{\text {rd }}$ December 2010

[3] EirGrid Grid Code (Republic of Ireland)

[4] Siemens (http://www.energy.siemens.com)

[5] Coughlan, Y., Smith, P., Mullane, A., and O'Malley, M., 2007, "Wind Turbine Modelling for Power System Stability Analysis - A System Operator Perspective, , IEEE Transactions on Power Systems, Vol. 22, No 3

[6] Christiansen, W., and Johnsen, D., 2006, "Analysis of the requirements in selected grid codes"

[7] Clark, K., Miller, N., and Sanchez-Gasca, J., 2008, "Modeling of GE wind turbine-generators for grid studies", GE Wind turbine model technical guide

[8] "Large scale integration of wind energy in the European power supply: analysis, issues and recommendations", 2005, EWEA

[9] "Procedure for verification, validation and certification of the requirements of the PO 12.3 on the response of wind farms in the event of voltage dips", 2007, Asociación Empresarial de Eólica (Spain)

[10] Transmission Code 2010, Swissgrid (Switzerland)

[11] "Harmonising Europe's Grid Codes for the Connection of Wind Power Plants to the Electricity Network", 2009, EWEA

[12] "Generic Grid Code Format for Wind Power Plants", 2009, EWEA

[13] Image sourced from Pelamis Wave Power Ltd. website (www.pelamiswave.com)

[14] Image sourced from AWS Ocean Energy Ltd. website (www.awsocean.com)

[15] Image sourced from the website of the University of Strathclyde (http://www.esru.strath.ac.uk)

[16] Image sourced from Aquamarine Power Ltd. website (www.aquamarinepower.com)

[17] EMEC website: http://www.emec.org.uk/

[18] Image sourced from the Marine Institute of Ireland, "Annual average wave height"

[19] Tissandier, J., Babarit, A., and Clement, A.H., 2008, "Study of the smoothing effect on the power production in an array of SEAREV wave energy converters", ISOPE

[20] Distribution Code, 2007, ESB Networks (Republic of Ireland)

[21] O'Sullivan, D., Mollaghan, D., Blavette, A., and Alcorn, R., 2010, "Dynamic characteristics of wave and tidal energy converters \& A recommended structure for development of a generic model for grid connection", Final Annex III Technical report, OES-IA document No T0321

[22] "Generic Type-3 Wind Turbine-Generator Model for Grid Studies", WECC Wind Generator Modeling Group, 2006

[23] IEC group TC 114 "Marine energy - Wave, tidal and other water current converters"

[24] Equimar project http://www.equimar.org/

[25] Nielsen, K., "Development of Recommended Practices for Testing and Evaluating Ocean Energy System", 2010, Annex II Technical Report, OES-IA document No T02-0.0

[26] DIgSILENT website: http://www.digsilent.de/

[27] PSCAD® website: https://pscad.com/products/pscad
[28] PowerTech website: http://www.powertechlabs.com

[29] Distribution Code, 2007, DCC11.3.4, ESB Networks (Republic of Ireland)

[30] British Grid Code, 2010, Issue 4, revision 4

[31] Image sourced from Wikipedia, article "Tehachapi Pass Wind Farm"

[32] Image sourced from the Danish Wind Energy Association website (http://guidedtour.windpower.org/en/core.htm)

[33] Image sourced from Encyclopaedia Britannica article"Portugal"

[34] Image sourced from the Central Statistics Office Ireland, "Population density of the Electoral divisions, 2006" 